\title{
OS QUATRO MODELOS DE ESPAÇO-TEMPO E A REESTRUTURAÇÃO*
}

\author{
RUY MOREIRA \\ Universidade Federal Fluminense
}

\begin{abstract}
A reestruturação por que vem passando a economia e a sociedade industriais no Brasil e no mundo tem algumas componentes que indicam estar em curso algo mais que uma simples mudança de regulação produtiva. Em que consiste a reestruturação e como podemos formular seu conceito? Qual o significado da reestruturação no Brasil?
\end{abstract}

\section{A reestruturação e os quatro modelos de espaço-tempo}

A reestruturação refere-se às formas e escalas de espaço-tempo das sociedades modernas. Neste sentido, combinam-se numa só quatro reestruturações de forma-escala neste começo de milênio - que designaremos modelo histórico mundial, modelo histórico brasileiro, modelo de acumulação brasileiro e modelo industrial brasileiro —, segundo as quais até agora se ordenaram as sociedades capitalistas no mundo e no Brasil, numa concomitância de ocorrências que, mais que uma troca, sugere a passagem a algo mais próximo de um novo ciclo da organização histórica do capitalismo.

O pressuposto é o fechamento do processo de constituição industrial do capitalismo, ou do capitalismo como sociedade industrial, fase que somente agora se completa como etapa com a escala da planetarização, abrindo para o capitalismo como um sistema pleno e maduramente realizado como modo de produção e cultura mercantil (MOREIRA, 1998 e 2001a).

Cabem algumas palavras sobre o conceito de modelo aqui empregado. Entender-se-á por modelo um dado modo de estruturação das relações entre economia e política dentro de uma sociedade dada, o amálgama de um todo em que a política governa a organização da economia por intermédio de um dado modo de regulação, ao tempo que desta é emanada. De maneira que a política deixa de ser uma pura condição geral de gestão, para relacionar-se com a economia como sobre-determinação.

Acresce que quem fala de política como sobre-determinação da economia, fala de uma ênfase posta na ação do Estado. Adiante-se que o Estado será entendido aqui como uma relação de pactuação estabelecida entre os sujeitos dominantes do modelo histórico, na qual a ideologia, entendida como a cultura criada pelos intelectuais para o fim de legitimar o pacto na história, ocupa um papel chave (GRAMSCI, 1968a e 1968b). Situações, ambas, típicas do capitalismo

\footnotetext{
* Texto elaborado para orientação de linha da pesquisa A Reestruturação Produtiva Brasileira e o Novo Modelo Industrial do Estado do Rio de Janeiro, Projeto Integrado do CNPq em realização no âmbito do GERET (Grupo de Estudos de Reestruturação do Espaço e do Trabalho), do NURET (Núcleo de Estudos de Reestruturação do Espaço e do Trabalho), Departamento de Geografia, Universidade Federal Fluminense, do qual são co-autores os bolsistas de iniciação científica Laura Nunes Bernardes Peixoto, Glauco Bruce Rodrigues, Vinicius Borges de Freitas Rodrigues e Ethel Guedes Vieites.
} 
avançado (MANDEL, 1984).

Os quatro modelos são, a um só tempo, distintos e combinados.

Distinguem-se e combinam-se, primeiramente, o modelo histórico e o modelo de acumulação. O modelo histórico é o arco de longa duração de tempo de uma dada estrutura de relação política-economia na sociedade. O modelo de acumulação é o recorte estrutural desse modelo histórico, definido a partir de um ramo-base da economia, o mais dinâmico de cada momento, de onde emanam os estímulos que articulam todos os demais ramos numa estrutura e num dinamismo que faz o sistema econômico movimentar-se como um todo. O Estado é o elemento-chave da integração desse todo metabólico. Sob sua instância, forma-se a estrutura integrada dos ramos e serviços ao redor do ramo-base que retroage até à retaguarda agrícola no campo. Assim, o dinamismo do ramo-de-ponta se irradia para a totalidade dos demais ramos e setores, infundindo um ritmo e um perfil ao todo econômico que o Estado cuida de fazer acontecer através das suas políticas econômicas. Distinguem-se e combinam-se, por fim, o modelo histórico, o modelo de acumulação e o modelo industrial. Sendo o modelo histórico e o modelo de acumulação o que vimos, por modelo industrial entendemos o modelo histórico onde o modelo de acumulação está centrado na indústria, numa relação em que a indústria atua como a base e a agricultura como retaguarda do processo acumulativo, dentro de uma coligação sociedade civil-Estado definida a favor da industrialização como eixo do desenvolvimento global. É assim que se pode falar de um modelo industrial inglês (clássico), modelo industrial americano, modelo industrial tardio (germânico, italiano e japonês), modelo industrial soviético, modelo industrial brasileiro.

Resumindo a relação entre os três modelos de outra maneira, a combinação dos modelos histórico e de acumulação forma o modo de desenvolvimento, de que o modelo industrial é o melhor exemplo.

Vejamos essas combinações nos modos de desenvolvimento ocorridos no Brasil e no mundo.

\section{O modelo histórico e de acumulação brasileiro}

A sociedade brasileira evoluiu historicamente com base no que se chama modelo concentrador e excludente. Concentrador no sentido da desigual distribuição da riqueza e da renda. Excludente, no sentido da marginalização da maioria da população do poder de decisão dos caminhos e formas de organização da sua própria sociedade.

A origem da concentração econômica e da exclusão política é uma sociedade centrada no monopólio. Monopólio da propriedade dos escravos, e assim monopólio da propriedade da terra, na origem; monopólio dos frutos de uma espécie de acumulação primitiva interna, a seguir; e monopólio do dinheiro, da indústria e dos serviços básicos nos dias atuais, por fím.

$\mathrm{Na}$ fase inicial não há um Estado brasileiro, mas um Estado Colonial português, do qual a Colônia-Brasil faz parte (NOVAIS, 1979). A terra é objeto de concessão pela Coroa portuguesa à elite na forma de sesmarias, o critério sendo o número de escravos sob propriedade do beneficiário (FURTADO, 1961). Quanto maior o plantel de escravos, maior a extensão de terras a receber. E assim sucessivamente. De modo que poder e riqueza são parte de um sistema de monopólio. O objeto de todo o empreendimento é o mercado mundial, de modo que não se forma uma classe estritamente agrária, já que o mercado externo é o destino e a razão do sistema. Isto 
determina um perfil de sociedade cuja estrutura combina relação agrária na base e relação de mercado no topo, numa simbiose que determina todas as características de espaço-tempo do modelo. Já começa que o sentido agro-mercantil segmenta a organização do espaço no tempo, criando-o e recriando-o segundo seus distintos momentos. Assim, em cada momento do tempo, um produto-rei predomina sobre os outros, produzindo um espaço regional distinto. E diversos espaços regionais se formam e coabitam o espaço da colônia na medida que esta evolui, criando com o tempo a sensação de um conjunto de ilhas que não se comunicam, voltadas para si e só se abrindo para o mercado externo. Sensação que se desvanece diante da ação gestora do Estado, que num pacto agro-mercantil por cima integra jurídico-politicamente numa só unidade de território a totalidade dos fragmentos dos espaços dos ciclos, suprimindo-lhes a falsa impressão de arquipélago (MOREIRA, 1981).

Todo esse sistema social é movido pelo modo como o capital acumula, dito modelo de acumulação agro-mercantil escravista. As classes sociais do modelo, o que produz, o destino dado, o modo de produção de cada um dos produtos, são o que vimos. Produz-se açúcar de cana, tal como hoje. Mas uma coisa é a cana do tempo da escravidão, outra é a cana dos dias de hoje, do ponto de vista das relações de produção e de classe que o produto socialmente encarna. $\mathrm{O}$ açúcar pode ter o mesmo sabor, mas não tem o mesmo tempero social, em suma. O modo de acumulação segue um esquema simples: o escravo produz o excedente, que o senhor expropria e reparte com a burguesia-comerciante em seu papel de intermediária mercantil-financeira (MOREIRA, 1981). O ciclo se repete para cada produto-rei, em cada segmento de espaço-tempo e em todo o correr do agro-escravismo.

A emergência da ordem burguesa não altera este modelo fechado na elite. Antes, exige que se passe por uma fase de transição na qual o escravismo dê lugar a uma sociedade centrada num contratualismo verbal, que de concreto será ainda fortemente a relação de trabalho do escravismo. Realizada sem acompanhamento de uma reforma agrária que toque na força e no poder do monopólio, a abolição que substitui o trabalho escravo pelo contratual do assalariado não fere a natureza concentradora e excludente do modelo escravista, e, quase que numa substituição por recriação, todos os problemas e vícios da estrutura escravista se passam para a fase seguinte da evolução brasileira. A regência dessa transição realiza-o o modelo de acumulação primitiva interna proto industrial. O Brasil entra na nova fase criada pela abolição da escravatura, a proclamação da república e a instituição do Estado nacional brasileiro (para muitos estudiosos só então se pode falar de uma cultura e uma literatura brasileira próprias, mercê de uma economia e um Estado nacional próprios). E se transforma numa sociedade estruturada no trabalho do seringueiro, do condiceiro, do peão e do colono, formas regionais do trabalho surgidas da abolição do trabalho escravo no âmbito do velho arcabouço, um "arquipélago" agora transformado num modelo de regiões homogêneas, diferenciadas pela forma da acumulação primitiva (MOREIRA, 1989 e 1990). Aqui já não se trata mais de produzir para a acumulação de fora, ficando-se com as sobras do excedente exportado. Fração crescentemente importante do excedente fica agora retida no circuito econômico interno por meio do envolvimento de meios espaciais de produção fixos e de contingentes demográficos consumidores dos produtos aqui gerados. A economia segue sendo agro-exportadora, mas o sobre-trabalho é crescentemente acumulado nacionalmente.

É assim que chegamos à sociedade industrial que hoje conhecemos. A permanência de um modelo concentrador e excludente dentro de uma sociedade altamente urbano-industrializada 
é um paradoxo que pede uma explicação consistente. Vários são os estudos e hipóteses sobre a origem da sociedade industrial brasileira. Inspirada no modelo explicativo montado para analisar a evolução industrial de São Paulo, a teoria da evolução histórica do Brasil vigente vincula a industrialização nacional à acumulação cafeeira. Válida para explicar a concentração industrial em São Paulo, duvidamos da universalidade dessa teoria para o todo da evolução nacional. Parece-nos mais acertada uma teoria que vincule o nascimento da indústria, assim como do sistema bancário e de todo o terciário, a uma acumulação primitiva interna. $\mathrm{O}$ que é dizer um processo espacialmente diferenciado, porque alicerçado no espaço-arquipélago e ocorrente em cada uma das regiões, cada qual com características marcadamente próprias, inclusive a região cafeeira (MOREIRA, 1989). A concentração industrial em São Paulo, isso é outra história, mercê de uma política de financiamento da indústria paulista com os recursos transferidos das diversas exportações de produtos regionais para São Paulo pelo governo federal. Seja como for, a hipótese de que nos servimos é que a elite agrária não desaparece com a nova fase. De início, sua presença e poder até se robustecem, mercê da absoluta relação de intimidade que tem com o Estado patrimonialista e cartorial, Estado gerado pelo próprio processo da concentração e exclusão, modernizando-o e modernizando-se ao compartilhá-lo com as frações sócio-econômicas urbanoindustriais oriundas de metamorfoses de segmentos da própria elite a partir da acumulação agromercantil. $\mathrm{O}$ fato é que não vingou um modelo político de separação entre o público e o privado, característico do Estado burguês, no Brasil, onde o Estado funciona como um poder público separado de uma sociedade civil autônoma. O monopolismo histórico do modelo agro-mercantil impediu essa possibilidade, antes a elite optando por uma fronteira cinza e absolutamente indivisa entre sociedade e Estado, ao originar uma sociedade viciada na intervenção e tutela do Estado. É a acumulação industrial, o modelo de acumulação que rege o modelo histórico neste momento. A natureza industrial da acumulação radicaliza o voltar-se para dentro. Peça importante desse modelo é a intervenção do Estado, instalando a infra-estrutura de base, regulando as forças do mercado, implementando os setores de indústria de sentido estratégico, balizando o modo do desenvolvimento através do planejamento. A face da sociedade e do espaço mudam radicalmente. As classes sociais da acumulação primitiva dão lugar a uma massa de trabalhadores urbanos em ampliação acelerada. O atraso, à modernidade tecnológica. E os mercados se unificam e se hierarquizam, unificando e hierarquizando o espaço brasileiro nacionalmente. $O$ Brasil se transforma numa sociedade urbana e de massas.

Por fim, instala-se a sociedade da hegemonia financeira. $\mathrm{O}$ modo de acumulação financeira que se abanca, internacionaliza o espaço nacional, globaliza o mercado, por conta da qual a bolsa e o crédito organizam a sociedade nos termos da financeirização e da securitização do sistema (BRAGA, 1998; MOREIRA, 1999c). O de dentro se abre para uma economia sem fronteiras que avança em todo o mundo. E a fase de reestruturação, em que ora nos encontramos.

\section{O modelo industrial}

O momento áureo desse processo histórico é o modelo industrial brasileiro. Chamado modelo de industrialização substitutiva de importações (TAVARES, 1977).

O mecanismo processual é conhecido: uma combinação de dificuldades de exportar e importar que leva a demanda de bens industriais a ter-se que contentar com a produção interna, estimula-a a expandir-se incessantemente, atuando como impulsão industrial, numa sucessão de 
quatro fases por meio das quais a industrialização se completa e toma a economia nacional um sistema industrialmente auto-sustentado.

Três fases se distinguem particularmente, cada qual correspondendo a uma forma específica de impulso industrialista: a substitutiva de bens de consumo não-duráveis, vinculada à primeira grande guerra; a substitutiva de bens intermediários e de equipamentos, vinculada à crise de 1929-1930; e a substitutiva de consumo durável, vinculada ao período pós segunda guerra. Pode-se falar ainda de uma quarta fase, a substitutiva de insumos industriais para a agricultura, dos anos setenta-oitenta.

A fase da industrialização substitutiva de importação de bens não-duráveis ocorre entre as décadas de dez e quarenta do século XX. A dificuldade de exportar criada pela explosão da guerra nos tradicionais centros de consumo dos agro-produtos brasileiros, traduzida numa incapacidade de importar dado a insuficiência de divisas, volta a demanda interna para a parca produção nacional então existente, impulsionando-a.

A fase da industrialização substitutiva de importação de bens intermediários e de equipamentos ocorre entre as décadas de trinta e sessenta. No fundo, esta fase é um efeito da finalização da primeira e da demanda de infra-estrutura e equipamentos então criada. Nas quatro décadas que se processa o desenvolvimento dessa fase, aparecem as implementações da produção do aço, do cimento, da energia, e dos derivados de petróleo, seguidas dos ramos petroquímico, transportes e metal-mecânico. Simultaneamente, multiplicam-se e ramificam-se as vias de transporte, de telecomunicação e de transmissão de energia, integrando entre si as áreas do país e eliminando os resíduos que ainda restavam da fase do "arquipélago".

A fase da industrialização substitutiva de importações de bens de consumo durável ocorre nas décadas de sessenta-setenta, praticamente em concomitância com o momento final da segunda.

A fase da industrialização substitutiva de insumos industriais agrícolas, por fim, vem na década de oitenta, demandada pela rápida modernização do campo que integra indústria, sistema bancário e agricultura uns com os outros, e culmina no desenvolvimento auto-sustentado do país.

Dois regimes de acumulação agrupam em duas distintas estruturas estas quatro fases do modelo de industrialização substitutiva: o de base no ramo têxtil, da fase substitutiva de bens de consumo não durável, e o de base no ramo automobilístico, das demais fases.

A demanda de matérias-primas brutas e equipamentos importados pelo ramo têxtil no primeiro regime de acumulação e de equipamentos gerados internamente e matérias primas semimanufaturadas pelo ramo automobilístico no segundo, são os indicadores que orientam a articulação do conjunto dos ramos e setores econômicos e determinam o modo de organização da agricultura e de intervenção do Estado com suas políticas públicas.

O modelo de acumulação de base têxtil-ferroviário-portuária leva a um modelo de agricultura centrada na produção de divisas de exportações, com as quais financiam-se as importações de equipamentos, e na produção de alimentos, com os quais determina-se a política salarial da indústria. O modelo de acumulação de base automobilística leva a um quadro de oferta de bens de equipamento e infra-estrutura de energia, telefonia e transportes rodoviários que expande os ramos de eletro-domésticos e automóveis e integra em seu dinamismo a totalidade dos ramos de indústria e serviços urbanos e um modelo de agricultura com o qual o campo experimenta um crescimento jamais visto.

Ao longo de todo o período do modelo substitutivo, recobrindo sucessivamente suas 
quatro fases, por sua vez, o Estado intervém sob formas as mais variadas: aqui, via política de financiamento da industrialização pelo sistema de câmbio e ágio pagos pelas exportações agrícolas; acolá, via implantação da infra-estrutura de transportes, comunicações e energia. Em todo lugar, via resposta à demanda de insumos básicos à produção industrial, com a produção de aço, energia e derivados de petróleo pelas empresas estatais. Por meio de um sistema de taxas e tributos pagos por toda a sociedade, o Estado subsidia o fomento industrial O mecanismo é a política do planejamento, do Plano SALTE dos anos quarenta aos PNDs dos anos oitenta.

\section{O modelo histórico mundial}

Todas estas fases se integram num modelo histórico mundial que pode ser repartido em três diferentes segmentos de espaço-tempo: o primeiro, estendido do renascimento no século XIV ao iluminismo no XVIII; o segundo, do iluminismo do século XVIII ao advento do capitalismo tardio dos meados do século XX; o terceiro, do capitalismo tardio do século XX ao capitalismo globalizado das décadas finais do século XX e iniciais do século XXI (MOREIRA, 1999b).

O primeiro é o período da acumulação primitiva européia, dominado pela acumulação mercantil, um processo de nível mundial cujo rebatimento é a sociedade colonial-escravista do modelo histórico brasileiro (FRANK, 1977 e 1980). O capital mercantil, a forma de capital que primeiro surge na história do capitalismo, controla a vida econômica e política dos produtores, um conjunto tanto local (artesãos e camponeses) quanto mundial (plantacionistas) de produtores não-capitalistas, do que resulta uma distribuição espacial mundial desigual e atomizada que só a esfera da circulação anima e organiza (MOREIRA, 1986). O comerciante compra os produtos por um preço barato num canto, para revendê-los num outro por um preço mais elevado, acumulando com a diferença. Situação que leva a arrumação difusa e indiferenciada do espaço existente a dar lugar lentamente ao espaço organizado das regiões homogêneas, um processo que dar-se-á no Brasil a partir da configuração aparentemente confusa do espaço-arquipélago.

O segundo é o período dominado pela acumulação industrial. A forma-valor da acumulação é a mais-valia produzida dentro da fábrica sob o comando direto do capital produtivo - que é o capital industrial -, do que decorre uma inversão na relação das esferas econômicas, a esfera da produção assumindo o comando da integração e organização do espaço, antes realizada pela esfera da circulação, dando um novo rumo à economia. Então, uma espécie de acumulação primitiva é iniciada nas ex-colônias, generalizando-se para tornar-se a lei de desenvolvimento do espaço mundial. Diferentes estágios desse processo - completado em algumas partes, mal começado em outras, já muito à frente em outros ou ainda nem mesmo chegado à primeira fase -, recortam territorialmente o espaço mundial num quadro desigual-combinado de desenvolvimento (que os geógrafos dos anos 50 e 60 irão interpretar como o mapa dos diferentes estados de subdesenvolvimento dos países (LACOSTE, 1968 e 1969), numa equivocada teoria trimundista de formação do mundo moderno). Dois distintos momentos, entretanto, diferenciam-se neste período, correspondentes respectivamente à primeira e à segunda revolução industrial. $\mathrm{O}$ momento que vimos é o correspondente à primeira revolução industrial, fase em que os espaços recém-saíram do período da acumulação primitiva, agora em ocorrência nas ex-colônias mundo afora, e guardam ainda os traços e características de organização uniforme e tecnicamente pouco transformados das regiões homogêneas. $\mathrm{O}$ momento seguinte é o correspondente à segunda revolução industrial, fase do capitalismo avançado, marcado pela alta escala de concentração 
tecnológica dos processamentos produtivos, pelas normas da regulação fordista e pela forte presença normativa e empresarial do Estado. É o momento em que os diferentes estágios dos países centrados no processo da acumulação primitiva interna deságuam na mesma contemporaneidade do capitalismo pleno com que se fecha o ciclo da capitalização tardia em todo o mundo, de modo que não há mais canto onde as relações econômicas, políticas, culturais, não sejam já as do modo de produção e da cultura de mercado do capitalismo (MOREIRA, 2001a).

$\mathrm{O}$ terceiro, por fim, é o dominado pela acumulação financeira. E o período em que o fim do ciclo da industrialização mundial abre para a fase da globalização financeirizada. A formavalor se descola do valor operário-fabril, o capital passando a incorporar todo tipo de excedente ou meio que possa converter em acumulação. E o valor e o trabalho tornam-se ambos entes polissêmicos (MOREIRA, 1999c).

\section{A crise dos modelos e o conceito de reestruturação}

A reestruturação é esta transição do industrial ao pós-industrial. Algumas considerações devem aqui ser feitas.

A primeira questão refere-se à natureza da reestruturação. Apontamos acima o pressuposto de que a industrialização em que os países entram no correr das décadas de trinta a oitenta é a culminância de uma espécie de acumulação primitiva nacional que ocorre numa escala de generalidade a partir da segunda metade do século XIX, levando cada canto do mundo a industrializar-se. O modo de produção e a cultura de mercado capitalistas saem assim do seu reduto europeu, para tornarem-se um modo de vida geral da humanidade. Uma ideologia de subdesenvolvimento (semelhante à ideologia atual do meio ambiente) se espalha internacionalmente em vista disso, com o fito de empurrar os países então ditos pré-industriais a industrializar-se, através da criação do constrangimento de ser sub, sinônimo de atrasado, que leva povos e governos a uma arrancada industrial num tempo sem precedentes (é o Brasil dos "cinqüenta anos em cinco"). Em menos de meio século o mundo se industrializa, um feito fantástico se lembrarmos que a Inglaterra levou praticamente um século (1760-1830) para tanto.

Esta arrancada industrial em nível generalizado de mundo coincide com o estágio avançado do fenômeno do imperialismo, analisado por Lênin (1979). Mais que apoiar as relações internacionais na exportação de capitais, traço assinalado por Lênin, através da industrialização generalizada o capital instaura agora a lei do valor-trabalho como fundamento sócio-econômico de todos os lugares do mundo.

O resultado é a divisão internacional inter-industrial de trabalho e de trocas que substitui a velha divisão e trocas de manufaturados e matérias-primas entre países industriais e préindustriais, cujo auge foi a década de 50, integrando e padronizando os mercados na escala global e financeira que hoje conhecemos.

Conseqüentemente, mais que uma superação das formas de regulação industrial, a reestruturação é pois uma nova forma de relação economia-política, centrada não mais na indústria mas na finança. Daí atingir desde o mundo do trabalho (a substituição toyotista) até ao do Estado (a despatrimonialização, a privatização e a desregulamentação), numa totalização de abrangência que recria e reordena por inteiro os modelos, os blocos históricos e seus pactos.

A segunda questão relaciona-se à ligação da reestruturação com a concomitância do esgotamento dos modelos. A sincronicidade do esgotamento das escalas de espaço-tempo-mundo 
e espaço-tempo-Brasil é o aspecto básico da natureza e movimento da reestruturação. Não por uma simples coincidência, o modelo histórico mundial e o modelo histórico brasileiro se esgotam, quando ambos se esgotam no mesmo tempo.

Em todos os cantos do mundo verifica-se esta sincronicidade de esgotamento de modelos. E é nesse sentido que se pode falar de uma convergência das escalas de tempo, o tempo-mundo e o tempo-nacional no estilo do tempo-Brasil, confluindo num mesmo processo de reestruturação.

É como se uma história de unificação-uniformização de parâmetros que começou com a expansão mercantil à época das grandes navegações, estivesse agora fechando seu ciclo ao atingir a escala global da planetarização, só que para reabri-lo numa espécie de re-globalidade. $\mathrm{O}$ formato novo é que não se sabe o que será.

Esclareçamos. O que hoje se materializa como globalização começa com a empiricização das categorias de valor universal da velha metafísica. O mundo de antes desse começo era o mundo diversificado da realidade sensível, com suas culturas e concepções imediatas de mundo. Já o mundo globalizado de hoje é aquele múltiplo da sensibilidade substituído pelo modelo único da universalidade metafísica (MOREIRA, 1997 e 1999a).

Dito de outro modo: aquilo que cada lugar é, é o que a filosofia chama de nosso mundo sensível, mundo que nossa percepção apreende através da visão, do olfato, de todas as formas da captação sensível. Assim, cada lugar é um lugar diferente. Este mundo múltiplo do sensível, com o tempo sofre uma rearrumação geral, tendo por trás e por dentro o conjunto dos conceitos, como a idéia de espaço-tempo métrico, que não é um dado do mundo sensível, que vai ganhando corpo e valor de extensão geográficos planetários. De modo que o que era sensivelmente diverso, vai se enquadrando na racionalidade conceitualmente uniforme da verdade em sua escala geográfica, até que, por fim, os mundos viram um só. Então, o que se entendia por bem, ordem, natureza, tempo e espaço num lugar, torna-se o mesmo para todos os lugares. O desejo metafísico dos filósofos torna-se realidade empírica. E o veículo disso é a uniformidade da técnica dos espaços.

É esse processo geográfico o que precisamente distingue a sociedade capitalista em comparação a outras formas de sociedade na história, que nunca ultrapassaram os limites territoriais acanhados dos seus lugares.

Contrariamente, o capitalismo é o tipo de sociedade que vive e se desenvolve exatamente da expansão geográfica dos universais metafísicos. O principal dos quais é o valor econômico (valor-trabalho). O valor é o alimento que nutre o capitalismo. O conceito que ele exige como a base sobre a qual todas as sociedades do mundo culturalmente se organizem. Qualquer outra forma de racionalidade não serve, não somará no projeto da globalização capitalista, agirá como um contra-espaço, uma negação geográfica. Eis porque, desde o renascimento, por dentro da sua cara física, a mercadoria transporta a lógica metafísica que organiza todos os cantos do mundo na mesma ordem conceitual de espaço e tempo, inventando um padrão de norma que é o mesmo para todo contexto - climático, sazonal, biológico - de ambiente. Um padrão universal válido para tudo e todos em todo o planeta.

É essa racionalização a trajetória de todos os modelos históricos que vimos. Por isso, no instante em que o capitalismo se materializa numa escala geográfica de sistema planetariamente realizado, coincidentemente o mundo entra no chamado período do pós-moderno. Pudera, uma vez que a globalização é o ponto de chegada, uma chegada desigual e combinada, tal como o fora antes a época das acumulações primitivas que a ela levaram, o problema é como estruturar-se o modelo histórico do capitalismo diante da metafísica já espacialmente concretizada. A re- 
globalização, talvez seja esta a resposta.

A terceira questão refere-se à natureza da presença do Brasil na relação Brasil-mundo, em termos de modelos históricos. Vimos que a reestruturação junta duas escalas: o tempo-espaço mundo e o tempo-espaço Brasil. Um arco de história longo, que chamamos de modelo histórico mundial, que se inicia com o começo e se fecha agora com o desfecho da globalização efetiva, e um arco de tempo, não menos curto, o do modelo histórico brasileiro, cuja trajetória percorre o mesmo arco de tempo do arco-mundo, se cruza com ele, mas com todo um conjunto de complicações teóricas. Pode-se por esta relação em termos reflexos?

Muitos são os que, como Prado Jr. (1979), entendem a história brasileira como um prolongamento da história mundial. Celso Furtado diz que a descoberta que dá início à história brasileira é um capítulo da expansão mercantil européia. Ambos tomam o que ocorre no Brasil como uma ressonância do que acontece no mundo externo. Então, o Brasil evoluiria tal como um dedo se desenvolve num corpo, acompanhando-o na mesma proporção da evolução deste. Confundir-se-iam, assim, as escalas de espaço-tempo mundo e espaço-tempo Brasil. Há, entretanto, os que, como Castro (1969), entendem o que ocorre no país como um moto próprio, o resultado das suas próprias leis de desenvolvimento, leis que dão à história de cada sociedade uma larga autonomia e possibilidades de acontecimentos nacionais distintos.

Seja como for, uma relação de diacronia-sincronia tem aqui lugar. O "de dentro" e o "de fora", que fazem a diferença desses modelos têm constituição diferente em cada um dos quatro momentos do modelo histórico. Sobremaneira, na relação interno-externa que caracteriza a fronteira espacial Brasil-mundo em cada modelo de acumulação. Na acumulação escravista, a produção é interna e a circulação externa. $\mathrm{Na}$ acumulação primitiva, a produção é interna e a circulação parcialmente interna. Na acumulação industrial, produção e circulação se fundem e se integram numa mesma internalidade fortemente. $\mathrm{Na}$ acumulação financeira, por fim, a produção e a circulação voltam a espacialmente separar-se, numa relação de interno e externo de difícil visualização de fronteira.

No primeiro caso, não haveria como condenar a elite brasileira pelo perfil e problemas do modelo histórico brasileiro. No segundo caso, ela seria a responsável pelo próprio modelo e seus modos de desenvolvimento.

Tomamos por princípio neste texto que o modelo histórico brasileiro é parte ao mesmo tempo indissociável e autônoma do modelo histórico mundial, que ora confunde-se com este modelo e ora dele se diferencia. Isso explicaria porque em certos momentos o modelo histórico mundial entra em crise, desanda, se esgota historicamente, tudo caminha estruturalmente para outro paradigma, enquanto que o modelo brasileiro, ao contrário, entra, exatamente neste momento, num período de dinamismo econômico e político enorme, a exemplo das correlações de crise e impulsão da industrialização substitutiva ocorridas já por duas ou três vezes (décadas de dez e de trinta, pelo menos), que a elite brasileira soube explorar muito bem.

Importando-nos analisar por que caminhos e por que meios o modo de acumulação industrial se reestrutura no Brasil, vejamos a marcha geral desse movimento.

O modelo da industrialização por substituição de importações chega ao esgotamento nos anos oitenta. E com ele o regime de acumulação apoiado no setor automotivo. A reestruturação produtiva, que desde então tem lugar, relaciona-se, em princípio, a esse esgotamento, indicando uma saída do modelo industrial.

Uma vez que a hipótese que seguimos é a da simultaneidade de esgotamento de conjunto 
dos quatro modelos, a reestruturação, para lá do modelo produtivo, estaria significando uma reestruturação mais ampla, revolvendo todas as escalas de espaço-tempo que até aqui estudamos. Altera a relação entre o público e o privado; mexe com a estrutura e perfil do Estado e sua relação histórica com a sociedade civil; sugere uma reestruturação do próprio modelo histórico capitalista, etc.

Provavelmente em razão dos modelos de acumulação respectivos raramente coincidirem no tempo, os modelos mundial e brasileiro acabaram evoluindo mais como duas escalas de espaço-tempo que integram-se e vivem momentos de conflitamento que duas formas de história que se confundem ou não se cruzam em nenhum momento. $\mathrm{O}$ fato é que há momentos em que não se sabe se a história brasileira é nacional ou mundial. E há os em que a sociedade brasileira destoa de tal maneira dos acontecimentos internacionais, que nacional e mundial acontecem como realidades particulares.

Pelos indícios que temos, as escalas do modelo histórico mundial, do modelo histórico brasileiro e a industrialização substitutiva de importação esgotam-se como modelos exatamente no mesmo momento, sugerindo neste caso um sincronismo de espaço-tempo que explicaria a forma da reestruturação produtiva brasileira e a simultaneidade com o que está acontecendo no mundo.

De modo que o esgotamento do modelo de industrialização por substituição de importações revela e expressa no Brasil o esgotamento simultâneo dos quatro modelos.

Sempre houve reestruturação na história, mundial e brasileira. As formas de reestruturação passadas viveram, todavia, momentos de diacronismo, em que o que acontecia numa escala de tempo não acontecia necessariamente na outra. O que ocorria na escala da história mundo, por exemplo, não era o que se via na escala da história brasileira, como no exemplo do modelo industrial brasileiro. A novidade do nosso tempo é a sincronia, mercê da simultaneidade do esgotamento dos quatro planos. Assim, no mesmo momento em que tem que entrar num novo modelo histórico, o Brasil tem que entrar num novo modelo de acumulação, e assim num novo modelo de desenvolvimento. Isto como exigência de acompanhamento da entrada do mundo do capitalismo num novo momento histórico.

Uma quarta questão refere-se ao problema essencial do modelo histórico brasileiro, isto é, ao tema da sociedade civil e sua relação com o Estado (CARVALHO, 2001). Uma sociedade civil autônoma diante do Estado, sempre dirigente nas decisões dos rumos e da política econômica geral, eis o grande hiato do modelo.

A evolução brasileira segue ao tempo que reitera permanentemente o modelo de Sociedade centrada no Estado. O Estado define as políticas, aponta as prioridades, determina a direção dos interesses. A sociedade civil move-se dentro das linhas desse limite, aceitando as determinações do Estado sem nem mesmo ser por ele consultada. Uma característica que se reforça mesmo quando a sociedade brasileira se torna um fenômeno de massa com a urbanoindustrialização. Aqui, é ainda o Estado que define, inclusive os valores intelectuais que orientam o comportamento, o modo de ver, perceber e vivenciar o trabalho e o lazer na cultura de massa, numa falência do intelectual de esquerda gramsciano. De modo que a cidadania política, atributo de uma sociedade tipicamente burguesa, não existe no Brasil, na mesma medida que inexiste a sociedade civil.

Berço histórico do modelo brasileiro haveria na sociedade colonial-escravista algo parecido a uma sociedade civil que desabrochasse no tempo? Sabemos hoje que a sociedade 
escravista no Brasil não é composta só de senhores e escravos. Há toda uma série de outros segmentos sociais, só agora investigados, que inclui homens livres urbanos e nas áreas rurais de fronteira (FRANCO, 1976). Dentro do espaço da ordem monopolista encontra-se o contra-espaço (MOREIRA, 2002a) dos homens livres urbanos e de fronteira. São homens excluídos da renda e da terra pelo sistema de sesmarias e do poder de decisão dos destinos da colônia pelo despotismo da Coroa e da elite. Mas os homens livres urbanos exercem um papel político restrito no dia-dia das cidades e o campesinato da fronteira cumpre o papel fundamental da manutenção do sistema com o suprimento alimentar das cidades, às vezes até da própria elite plantacionista das fazendas (MOREIRA, 1981). Considerando que a grande ordem manda, mas depende da pequena, representada pelos homens livres e camponeses na ordem escravocrata, poder-se-ia ver aí um embrião de sociedade civil que não vinga?

Sabemos que com a urbano-industrialização este contingente aumenta e socialmente se diversifica. Todavia, o processo industrial que urbaniza e dá novo conteúdo social ao modelo histórico da sociedade brasileira não engendra ainda uma sociedade civil que quebre o modelo concentrador-excludente característico.

Parece que só o estaria fazendo agora, quando, coincidindo com a crise do modelo industrial, começa a surgir o movimento de instituição de uma sociedade civil organizada no Brasil. Centra-o uma proclamação de cidadania, que se mantém, no entanto, ainda, dentro da tradição da cultura brasileira de usar palavras que não têm significado correspondente ao de um direito de decisão do poder político de fato. Quando se fala em cidadania no presente, fala-se do consumidor, uma falsa cidadania (SANTOS, 1987). E o Brasil continua a ser uma sociedade concentradora e excludente

No fundo, estamos diante do problema da revolução burguesa no Brasil (SODRÉ, 1963; PRADO JR, 1966; FERNANDES, 1974; IANNI, 1984). Vimos que a urbano-industrialização encaminha o modelo histórico brasileiro diretamente para o capitalismo e a sociedade burguesa correspondente, sem que o Estado deixe de ser a propriedade privada da elite, a política um direito de poucos e a distribuição da renda um reflexo de tudo isso. A revolução burguesa mantém e apenas reorienta o modelo concentrador e excludente da ordem escravista sob a cultura política do populismo.

O que identifica uma sociedade burguesa é a separação efetiva entre o público e o privado, permitindo que sociedade civil e Estado existam como pares independentes um do outro, a sociedade civil existindo efetivamente como o privado e o Estado efetivamente como o público. A representação aí é a essência da política. Por meio dela, a sociedade civil dá o sentido dos procedimentos, o poder público sendo desvinculado de todo o veso do patrimonialismo cartorial privado. No Brasil, isso significaria uma sociedade civil independente da tutela do Estado (correlatamente, de uma cultura de separação entre público e privado), a sociedade civil exprimindo-se no sentido de uma forma de mobilização popular organizada (popular no sentido de povo, não no sentido dos pobres) pela superação da concentração-exclusão econômica e política. E isto ainda está posto.

Uma quinta questão refere-se aos valores que regem o imaginário cultural brasileiro, fruto de um modelo histórico em tudo conservador. Duas heranças importantes advêm do modelo histórico brasileiro desse ponto de vista.

Em primeiro lugar, um certo cosmopolitismo, combinado a um certo caboclismo, como identidade da classe dominante brasileira. E, por extensão, do povo e da intelectualidade 
dominados. A elite tem uma cultura de classe rural, fechada em si e para dentro de si mesma, ao tempo que está aberta para o exterior, atenta para os refinamentos da elite externa, numa mistura de rudeza cabocla e finesse iluminista. Então, a cultura que ela respira, seus valores, são os valores desse sistema de sociedade que se enraiza na mesmice costumeira desse amálgama ao mesmo tempo de mundo rural fechado e de mundo industrial aberto para constantes mudanças. Valores da elite estrangeira, traduzidos em valores de uma elite interiorana e vinculada à terra, por conta de uma contabilidade e conceitos econômicos trazidos das praças de mercado externo, em resumo. Valores que se enraizam numa mentalidade conservadora, diferente de reacionária (FACÓ, 1960). E que se difundem e ganham aqui e ali sua forma intelectual e popular. Todo o imaginário do sertão nordestino, por exemplo, é tirado de Os Doze Pares de França, livro que narra epopéias da Idade Média européia, relacionadas aos cavaleiros de Carlos Magno, visão da elite nordestina, que, pela literatura de cordel, vira imaginário popular nordestino.

Em segundo, um persistente estrangeirismo da intelectualidade brasileira, fruto do reflexo da cultura conservadora e cosmopolita da elite, estampado entre outros na leitura do espaçotempo que essa intelectualidade faz da sociedade brasileira. Exemplifique-se com o conceito de cidade, de campo e de relação cidade-campo nada brasileiros com que ela interpreta a nossa realidade, de vez que no Brasil estabeleceu-se desde o começo um campo e uma cidade da elite rural-mercantil, fortemente relacionados entre si e com o que acontecia externa e internamente, o que significa um campo, cidade e relação cidade-campo em nada parecidos com aqueles da Europa, de onde conceitualmente viemos (MOREIRA, 1985) e persistentemente reiteramos, e que dificultam sobremaneira o efetivo nascimento do intelectual orgânico de esquerda analisado por Gramsci.

O que é, então, reestruturação? No geral, reestruturação é, portanto, o reordenamento da relação política-economia que informa todos os modelos. Vale dizer, a recriação, pelo sentido, dos modelos histórico e de acumulação. O que explica ter por centro de referência os esquemas da regulação. [Verdadeiramente falando, entretanto, reestruturação é a reorganização total da sociedade do trabalho, enquanto forma histórico-industrial do capitalismo, um formato que agora se esgota e se redefine em face do fim do ciclo da formação do capitalismo como sociedade industrial (MOREIRA, 2001b e 2002b). Tema a ser analisado em outro texto].

Global e ampla, acontecendo da regulação do trabalho à nova organização do Estado, pode-se por isso falar de uma reestruturação produtiva, industrial e espacial, expressões que remetem a recortes parciais do processo. A reestruturação produtiva refere-se à nova regra de regulação do trabalho no âmbito das fábricas, que consiste na troca das normas fordistas pelas normas toyotistas de organização. A reestruturação industrial remete às inovações tecnológicas da terceira revolução industrial. Desse ponto de vista, a reestruturação pode ser entendida como o conjunto das trocas de meios técnicos que centram os fabricos nos processamentos da microeletrônica e da informática, isto implicando a implementação das regras de flexibilização da produção e do trabalho da reestruturação produtiva, combinando e confundindo assim reestruturação industrial e reestruturação produtiva. A reestruturação estatal é o conjunto das reformas neoliberais do Estado, cujo exemplo é a transferência do patrimônio público para o poder privado, via privatização das empresas estatais. Por fim, a reestruturação espacial é o novo ordenamento territorial que emana disso tudo.

Daí que flexibilização, securitização, financeirização sejam os verbetes que melhor se abrem para o entendimento do movimento que transfere o centro de gravidade da economia 
mundial do comando industrial para o comando financeiro, substituindo a geografia de um espaço organizado na produção de mercadorias, o espaço-região, por uma outra de um espaço organizado na circulação do dinheiro, o espaço-tempo da rede.

Temos aí quatro faces de reestruturação, todas vistas como o processo combinado de desmonte-remonte de toda a institucionalidade capitalista criada no período industrial. Desmonte dos modelos de política econômica, pela despatrimonialização do Estado, desregulamentação das leis trabalhistas e privatização das empresas até então consideradas estratégicas para a constituição das economias nacionais, recriando a relação do Estado com o mercado industrial, com a finalidade de adequar as relações estruturais ao comando do capital financeiro. Remonte das territorialidades indicativas da centralidade do modelo industrial.

Daí reestruturação significar a eliminação das barreiras institucionais, jurídicas e espaciais que normatizam a produção nas fronteiras de uma configuração do trabalho fordista, cujos efeitos são o traçado de um novo modelo histórico no Brasil e no Mundo de recorte empírico ainda não de todo evidente.

\section{OS QUATRO MODELOS DE ESPAÇO-TEMPO E A REESTRUTURAÇÃO}

Resumo: A reestruturação é o processo de reorganização global da sociedade capitalista decorrente do esgotamento do seu ciclo de desenvolvimento industrial e da emergência das necessidades da acumulação financeira que ultrapassa e substitui o ciclo industrial na história. $\mathrm{O}$ texto é uma análise deste processo com o intuito de extrair dele um conceito de reestruturação válido para a compreensão do Brasil e do mundo nesta entrada do milênio.

Palavras-chave: Reestruturação, reordenamento do espaço, novo modelo de desenvolvimento.

\section{FOUR SPACE-TIME MODELS AND RESTRUCTURATION}

Summary: Restructuration is a process of global reorganization of capitalistic society, resulting from the prostration of its industrial development cycle and from the necessities of finantial accumulation that replace the industrial cycle in history. The text is analyse this process searching to obtain a valid concept of restructuration for comprehension of Brazil and the world in this beginning of millennium.

Keywords: Restructuration, reordering of space, new model of development.

\section{Bibliografia}

ARRIGHI, G 1996. O Longo Século XX: dinheiro, poder e as origens do nosso tempo. São Paulo-Rio de Janeiro: UNESP-Contraponto.

BAER, W. 1979. A Industrialização e o Desenvolvimento Econômico do Brasil. Rio de Janeiro: Fundação Getúlio Vargas.

BECKER, B. K. e EGLER, C.A. 1993. Brasil: uma nova potência regional na economia- mundo. Rio de Janeiro: Record.

BRAGA, J.C.S. 1998. Financeirização Global - o padrão sistêmico de riqueza do capitalismo contemporâneo. In TAVARES, M. C. e FIORI, J. L. (org.), Poder e Dinheiro (uma economia política da globalização). Petrópolis: Vozes.

CASTRO, A. B. 1969. 7 Ensaios Sobre a Economia Brasileira. 2 volumes. Rio de Janeiro: Forense Universitária

CARVALHO, J.M. 2001. Cidadania no Brasil: o longo caminho. Rio de Janeiro: Editora Civilização Brasileira

CHESNAIS, F. 1996. A Mundialização do Capital. São Paulo: Xamã. (org) 1997. A Mundialização Financeira: gênese, custos, riscos. São Paulo: Xamã

FACO, R. 1960. Brasil Século XX. Rio de Janeiro: Vitória.

FAORO, R. 1975. Os Donos do Poder: formação do patronato brasileiro. Rio de Janeiro: Globo

FERNANDES, F. 1974. A Revolução Burguesa no Brasil. Rio de Janeiro: Zahar. 
FRANCO, M. S.C. 1976. Homens Livres na Ordem Escravocrata. S. Paulo: Editora Atica

FRANK, A. G. 1977. Acumulação Mundial (1492-1789). Rio de Janeiro: Zahar.

(1980): Acumulação Dependente e Subdesenvolvimento. Repensando a teoria da dependência. São Paulo: Brasiliense

FURTADO, C. 1961. Formação Econômica do Brasil. Rio de Janeiro: Fundo de Cultura. 1998. O Capitalismo Global. Rio de Janeiro: Editora Paz e Terra

GRAMSCI, A. 1968a. Os Intelectuais e a Organização da Cultura na História. Rio de Janeiro: Editora Civilização Brasileira

1968b. Maquiavel e a Política do Estado Moderno. Rio de Janeiro: Editora Civilização Brasileira

HOBSBAWM, E. 1995. Era dos Extremos: o breve século XX - 1914-1991. São Paulo: Companhia das Letras.

IANNI, O. 2000. Enigmas da Modernidade-Mundo. Rio de Janeiro: Civilização Brasileira. 1996. Estado e Planejamento Econômico no Brasil. Rio de Janeiro: Civilização Brasileira. 1984 a. O Ciclo da Revolução Burguesa. Rio de Janeiro: Vozes. 1984b. Origens Agrárias do Estado Brasileiro. São Paulo: Brasiliense.

LACOSTE, Y. 1968. Os Países Subdesenvolvidos. Coleção Saber Atual, São Paulo: Difel. 1969. A Geografia do Subdesenvolvimento. São Paulo: Difel.

LENIN, V. I. 1979. Imperialismo: fase superior do capitalismo. São Paulo: Global.

LIPIETZ, A. 1988. Miragens e Milagres: problemas da industrialização no Terceiro Mundo. São Paulo: Nobel.

MANDEL, E. 1982. O Capitalismo Tardio. São Paulo: Abril Cultural.

MOREIRA, R. 1981. "Plantation" e Formação Espacial: as Raízes do Estado-Nação no Brasil, in Contribuição ao Estudo da Geografia Agrária. Rio de Janeiro: Departamento de Geografia-PUC. 1985. O Movimento Operário e a Questão Cidade-Campo no Brasil. Rio de Janeiro: Vozes. 1986. O Plano Nacional de Reforma Agrária em Questão. Terra Livre, ano 1, número 1. São Paulo: AGB. 1989. A Marcha do Capitalismo e a Essência Econômica da Questão Agrária no Brasil. Terra Livre, número 6. São Paulo: AGB. 1990. Formação do Espaço Agrário Brasileiro. Coleção Tudo é História no. 132. São Paulo: Brasiliense 1997. A pós-modernidade e o mundo globalizado do trabalho. Revista Paranaense de Geografia no. 2, Curitiba: AGB. 1998. Desregulação e Remonte no Espaço Globalizado. In Revista Ciência Geográfica no. 10, ano IV. Bauru: AGB. 1999a. Realidade e Metafísica nas estruturas geográficas contemporâneas. Redescobrindo o Brasil 500 Anos Depois, CASTRO, I. et al. (orgs.). Rio de Janeiro: Record. 1999b. O Paradigma e a Ordem: genealogia e metamorfoses do espaço capitalista. Revista Ciência Geográfica no. 13, ano V. Bauru: AGB.

1999c. A Diferença e a Geografia. O ardil da identidade e a representação da diferença na Geografia. GEOgraphia no. 1. Niterói: Programa de Pós-Graduação em Geografia-UFF. 200la . A globalização como modo de vida capitalista globalizado. Revista Ciência Geográflca no.19, ano VII. Bauru: AGB. 2001b. As Novas Noções do Mundo (Geográfico) do Trabalho. Revista Ciência Geográfica, no. 20, ano VIII. Bauru: AGB 2002 a. Espaço e Contra-Espaço: Sociedade Civil e Estado, Privado e Público na Ordem Espacial Burguesa. In: Santos, M. et al. Território, Territórios. Niterói, Programa de PósGraduação em Geografia-UFF/ AGB. 2002b. Teses Para Uma Geografia do Trabalho. Revista Ciência Geográfica no. 22, ano VIII. Bauru: AGB

NOVAIS, F. A. 1979. Portugal e Brasil na Crise do Antigo Sistema Colonial (1777-1808). São 
Paulo: Hucitec

PRADO JR., C. 1979. História Econômica do Brasil. 22a . ed. São Paulo: Brasiliense. 1966. A Revolução Brasileira. São Paulo: Brasiliense.

SANTOS, M. 1987. O Espaço do Cidadão. São Paulo: Livraria Nobel 2000. Por Uma Outra Globalização: do pensamento único à consciência universal. Rio de Janeiro: Record

SANTOS, M. e SILVEIRA, M. L. 2001. O Brasil: território e sociedade no início do século XXI. Rio de Janeiro: Record.

SODRÉ, N. W. 1963. Introdução à Revolução Brasileira. Rio de Janeiro: Civilização Brasileira

TAVARES, M. C. (1977): Da Substituição de Importações ao Capitalismo Financeiro: Ensaios sobre a economia brasileira. Rio de Janeiro: Jorge Zahar.

TAVARES, M. C. e FIORI, J. L. 1993. Desajuste Global e Modernização Conservadora. Rio de Janeiro: Paz e Terra.

TEIXEIRA, A. 1994. Ajuste Impossivel: um estudo sobre a desestruturação da ordem econômica mundial sobre o Brasil. Rio de Janeiro: Ed. UFRJ

TEIXEIRA, J. S. et al. 1996. Neoliberalismo e Reestruturação Produtiva: as novas determinações do mundo do trabalho. São Paulo: Cortez/UECE.

TIGRE,P. B. 2001. Indústria Brasileira: oportunidades e desafios. Revista de Economia Contemporânea no.3. Rio de Janeiro: Instituto de Economia da UFRJ.

THOMPSON, E. P. 1987. A Formação da Classe Trabalhadora Inglesa, 3 vols. Rio de Janeiro: Paz e Terra.

VELHO, O. G. 1976. Capitalismo Autoritário e Campesinato. Rio de Janeiro: Difel.

WIRTH, J. D. 1973. A Política de Desenvolvimento na Era Vargas. Rio de Janeiro: Fundação Getúlio Vargas. 